\title{
Can the Lung be Obese? The Effects of Bariatric Surgery on Lung Function and Imaging
}

Eva Rivas, MD, PhD ${ }^{1,2,3}$, José G. Venegas, $\mathrm{PhD}^{4}$ and Robert Rodriguez-Roisin, MD, PhD, FRCP, FERS $2,5,6$

${ }^{1}$ Servei d'Anestesiologia, Hospital Clínic, and ${ }^{2}$ Institut d'Investigacions Biomèdiques August Pi i Sunyer (IDIBAPS) and Fundació Clínic per a la Recerca Biomédica (FCRB), Barcelona, Spain; ${ }^{3}$ Outcomes Research Department, Cleveland Clinic Foundation. Cleveland, OH, US; ${ }^{4}$ Department of Anesthesia, Critical Care and Pain Medicine, Massachusetts General Hospital and Harvard Medical School, Boston, MA, US; ${ }^{5}$ Universitat de Barcelona, Barcelona, Spain; ${ }^{6} \mathrm{CIBER}$ de Enfermedades Respiratorias (CIBERES), Spain

\section{ABSTRACT}

Obesity is a state of low-grade chronic systemic inflammation that induces a reduction of adiponectin production with inhibition of the vasorelaxant properties of perivascular adipose tissue with underlying widespread endothelial dysfunction. This review concentrates on the main pulmonary and non-pulmonary determinants of gas exchange abnormalities, characterized by mild-to-moderate increased alveolar-arterial $\mathrm{O}_{2}$ difference, with or without mild hypoxaemia, in non-smoking morbidly obese subjects without associated relevant co-morbidities, candidates to bariatric surgery, induced by ventilation-perfusion imbalance and increased intrapulmonary shunt, including the effects of $100 \%$ oxygen breathing and those induced by postural changes. Likewise, we review lung imaging abnormalities, more specifically lung tissue volume, and their interaction with gas exchange disturbances. Finally, we address the long-term beneficial effects of bariatric surgery on all these obesity-induced lung function and imaging defects. Overall, we present a compelling evidence of lung function and imaging abnormalities underlying systemic and pulmonary inflammation in morbidly obese candidates to bariatric surgery. (BRN Rev. 2018;4:53-66) Corresponding author: Eva Rivas, erivas@clinic.cat; rivasfe@ccf.org

Key words: Bariatric surgery. Lung imaging. Morbid obesity. Postural changes. Pulmonary gas exchange. 


\section{INTRODUCTION}

Obesity is defined as an abnormal or excessive fat accumulation and body mass index (BMI) is the most useful outcome to classify overweight and obesity in human beings. However, Vague (1-3 $^{-3}$ was the first to describe, in 1947, that the greater the excess of abdominal fat (visceral intra-abdominal fat) the greater the risk factor for obesity-related disease. Thus, measurements of central obesity, waist circumference (WC) and waist-tohip ratio (WHR), are considered to be good descriptors of obesity and correlate with intra-abdominal and subcutaneous adipose tissue while providing a simple and practical method to identify obese subjects at highest risk ${ }^{2,4,5}$.

The worldwide rising prevalence of overweight and obesity has been described as a global pandemic $^{4}$ because, during the last 35 years, the number of overweight and obese individuals increased from 857 million to 1.9 billion, currently representing a global prevalence of $39 \% 6,7$. Moreover, the main burden of obesity lies on its interconnection with a number of metabolic and non-metabolic diseases including non-insulin-dependent diabetes mellitus, dyslipidaemia, arterial hypertension and atherosclerosis, leading by and large to a substantial increase in cardiovascular and cerebrovascular morbidity and mortality ${ }^{6-10}$. Given the rapid rise in obesity worldwide in recent years and the deleterious effects of both overweight and obesity in health and life expectancy, a thorough understanding of the physiological pathways of obesity relationships with or without multi-morbidities, including lung function abnormalities, becomes crucially important.

Alternatively, there are currently no truly effective pharmacological approaches to manage and treat obesity, especially in the morbidly obese individual. Moreover, diet therapy, with and without the support of health-care organizations, is relatively ineffective in treating severe obesity at the long-term. In 1991, the United States (US) National Institutes of Health established the indications of bariatric surgery in morbid obesity, namely BMI $\geq 40$ or BMI $\geq 35 \mathrm{~kg} / \mathrm{m}^{2}$ in the presence of significant multi-morbidities $^{11}$. It is of note, however, that bariatric surgery is the best currently available non-pharmacological treatment to achieve a sustained and significantly successful weight loss in severe obese subjects in whom the efforts of a medical therapy have failed ${ }^{12-15}$. More importantly, these beneficial effects are associated with a very low incidence of morbidity and mortality ${ }^{16-17}$.

\section{MECHANICAL COMPRESSION OF ADIPOSE TISSUE ON LUNG FUNCTION}

Obesity has a direct impact on respiratory well-being. The most consistently reported effect of obesity on lung function is a reduction in the functional residual capacity (FRC) and expiratory reserve volume $(\mathrm{ERV})^{18-21}$. Adipose tissue around the rib cage and abdomen and in the visceral cavity induces both thoracic external compression and cephalic migration of the diaphragm, hence reducing chest volume. Accordingly, there is an exponential relationship between BMI increases (even with modest weight gain) and decreases in FRC and ERV ${ }^{18}$. However, the effects of obesity on the extremes of lung volumes, i.e. total lung capacity (TLC) and residual volume (RV), and on forced spirometry, such as forced expiratory volume in $1 \mathrm{~s}\left(\mathrm{FEV}_{1}\right)$ and forced vital capacity (FVC), are modest with values slightly reduced or maintained within 
TABLE 1. Main findings in pulmonary gas exchange studies using arterial blood gases (ABGs), namely arterial $\mathrm{PO}_{2}$ and alveolar-arterial $\mathrm{O}_{2}$ difference in obese subjects

\begin{tabular}{|c|c|c|c|}
\hline $\begin{array}{l}\text { Authors, } \\
\text { publication year } \\
\text { [reference] }\end{array}$ & $\begin{array}{l}\text { Subjects } \\
\text { (n) }\end{array}$ & Before weight loss & After weight loss \\
\hline $\begin{array}{l}\text { Farebrother et al., } \\
1974^{23}\end{array}$ & 8 & $\begin{array}{l}\text { Arterial } \mathrm{PO}_{2} \text { and } \mathrm{ERV} \text { were lower when supine than } \\
\text { when upright }\end{array}$ & $\begin{array}{l}\text { Arterial } \mathrm{PO}_{2} \text { and } \mathrm{ERV} \text { values significantly improved } \\
\text { but were lower when supine }\end{array}$ \\
\hline $\begin{array}{l}\text { Vaughan et al., } \\
1975^{28}\end{array}$ & 22 & $\begin{array}{l}\text { In mild hypoxaemic obese women there were no } \\
\text { postural effects on ABGs before and at the third } \\
\text { day after conventional surgery }\end{array}$ & \\
\hline $\begin{array}{l}\text { Vaughan et al., } \\
1981^{27}\end{array}$ & 64 & $\begin{array}{l}\text { Morbidly obese patients have a marked reduced ERV } \\
\text { ( } 54 \pm 4 \% \text { predicted) and arterial } \mathrm{PO}_{2}(83 \pm 3 \mathrm{mmHg})\end{array}$ & $\begin{array}{l}\text { Significant weight loss is associated with gas } \\
\text { exchange improvement. There was a relationship } \\
\text { between ERV increase and arterial } \mathrm{PO}_{2} \text { and } \\
\text { alveolar-arterial } \mathrm{O}_{2} \text { difference improvements }\end{array}$ \\
\hline $\begin{array}{l}\text { Thomas et al., } \\
1989^{29}\end{array}$ & 29 & $\begin{array}{l}\text { Morbidly obese patients presented a marked reduced } \\
\text { ERV and mild hypoxaemia (arterial } \mathrm{PO}_{2}, 79 \pm 12 \mathrm{mmHg}\end{array}$ & $\begin{array}{l}\text { Significant weight loss is associated with marked } \\
\text { increases in ERV associated with slightly signifi- } \\
\text { cant increases in FEV1 and FVC. }\end{array}$ \\
\hline $\begin{array}{l}\text { Hakala et al., } \\
1995^{67}\end{array}$ & 8 & $\begin{array}{l}\text { In normoxaemic obese subjects, arterial } \mathrm{PO}_{2} \text { and } \mathrm{ERV} \\
\text { are lower when supine }\end{array}$ & $\begin{array}{l}\mathrm{ERV} \text { and } \mathrm{FRC} \text { improved significantly with weigh loss. } \\
\text { Arterial } \mathrm{PO}_{2} \text { improved in upright but not in supine position }\end{array}$ \\
\hline $\begin{array}{l}\text { Zavorsky et al., } \\
2008^{25}\end{array}$ & 25 & $\begin{array}{l}\text { Variance in the alveolar-arterial } \mathrm{O}_{2} \text { difference }(32 \%) \\
\text { and arterial } \mathrm{PO}_{2}(36 \%) \text { were explained by the WHR. } \\
\text { Compared to women, men had larger WHR }(\mathrm{p}<0.01) \\
\text { but not poorer gas exchange }(\mathrm{p}=0.06)\end{array}$ & \\
\hline $\begin{array}{l}\text { Zavorsky et al., } \\
2008^{24}\end{array}$ & 42 & $\begin{array}{l}\text { Mean arterial } \mathrm{PO}_{2}(81 \mathrm{mmHg}) \text { and alveolar-arterial } \mathrm{O}_{2} \\
\text { difference }(23 \mathrm{mmHg}) \text { were } 17 \mathrm{mmHg} \text { lower and } \\
\text { higher than predicted values }(98 \mathrm{mmHg} \text { and } \\
6 \mathrm{mmHg}) \text {, respectively }\end{array}$ & $\begin{array}{l}\text { Significant weight loss is associated with gas exchange } \\
\text { improvement. On average, for every } 5-6 \mathrm{~kg} \text { reduction } \\
\text { in weight, arterial } \mathrm{PO}_{2} \text { is increased by } 1 \mathrm{mmHg} \text { and } \\
\text { alveolar-arterial } \mathrm{O}_{2} \text { difference is reduced by } 1 \mathrm{mmHg}\end{array}$ \\
\hline $\begin{array}{l}\text { Zavorsky et al., } \\
2008^{26}\end{array}$ & 768 & $\begin{array}{l}\text { At rest, obese subjects have lower than predicted } \\
\text { arterial } \mathrm{PO}_{2} \text { and higher than predicted alveolar-arte- } \\
\text { rial } \mathrm{O}_{2} \text { difference compared to normal-weight healthy } \\
\text { controls. Compared to women, the worse gas } \\
\text { exchange in men is related to their higher WHR }\end{array}$ & \\
\hline $\begin{array}{l}\text { Gabrielsen et al., } \\
2010^{22}\end{array}$ & 149 & $\begin{array}{l}\text { There is a weak association between increased } \mathrm{BMI} \\
\left(\mathrm{r}^{2}=-0.28\right) \text { and } \mathrm{WC}(r=-0.33) \text { and decreased } \\
\text { arterial } \mathrm{PO}_{2}(\mathrm{p}<0.001 \text { each })\end{array}$ & \\
\hline $\begin{array}{l}\text { Arismendi et al., } \\
2014^{41}\end{array}$ & 149 & $\begin{array}{l}\text { Compared to controls }(\mathrm{n}: 20) \text {, obese subjects had } \\
\text { reduced forced spirometry and pulseoximetry, along } \\
\text { with diminished ERV and FRC values. ABGs were more } \\
\text { abnormal in men than in women with arterial } \mathrm{PO}_{2} \\
\text { values within normal limits while alveolar-arterial } \mathrm{O}_{2} \\
\text { difference were abnormally increased }(23 \pm 10 \mathrm{mmHg})\end{array}$ & $\begin{array}{l}\text { All lung function tests improved significantly with } \\
\text { increased ERV (106 } \pm 36 \% \text { of predicted). ABGs also } \\
\text { improved (arterial } \mathrm{PO}_{2} \text {, by }+11 \mathrm{mmHg} \text {; alveolar-arterial } 0_{2} \\
\text { difference, by }-14 \mathrm{mmHg} \text { ) }\end{array}$ \\
\hline
\end{tabular}

$\mathrm{N}$ : Subjects, size of the subset; BS: bariatric surgery; BMI: body mass index; ERV: expiratory reserve volume; FEV ${ }_{1}$ forced expiratory volume in $1 \mathrm{~s}$; FVC: functional residual capacity; $\mathrm{PO}_{2}$ : oxygen partial pressure; WC: waist circumference; WHR: waist-to-hip ratio.

the normal limits ${ }^{18-20}$. It is of note that the regional distribution of fat, in particular in central obesity, has an important effect on lung function. Thus, the higher the central obesity measured by both a larger WC and WHR, the more marked the ERV reduction ${ }^{22}$.
As expected, severe obesity is also associated with impaired pulmonary gas exchange (Table 1) ${ }^{22-29}$, which may increase the risk of post-operative pulmonary complications and have a deleterious effect on obesity-related multi-morbidities. Mild arterial hypoxaemia 
(arterial oxygen pressure $\left[\mathrm{PO}_{2}\right]<80 \mathrm{mmHg}$ ) and mild increases in the alveolar-arterial $\mathrm{O}_{2}$ difference ( $\geq 15 \mathrm{mmHg}$ ) are frequently associated with obesity $23,24,28,30,31$. In a review of 626 morbidly obese subjects when upright, arterial $\mathrm{PO}_{2}(81 \mathrm{mmHg})$ and alveolar-arterial $\mathrm{O}_{2}$ difference (23 $\mathrm{mmHg}$ ), values were in average $17 \mathrm{mmHg}$ lower and higher each than predicted normal values $(98 \mathrm{mmHg}$ and $6 \mathrm{mmHg}$, respectively $)^{26}$. Moreover, arterial $\mathrm{PO}_{2}$ and alveolar-arterial $\mathrm{O}_{2}$ difference were related to both overall BMI and central obesity (based on both WC and WHR) ${ }^{22,25}$; by contrast, arterial partial pressure of carbon dioxide $\left(\mathrm{PCO}_{2}\right)$ is usually preserved and remains within the normal range. It has been reported that men who have higher incidence of central obesity (larger WC and WHR) than women ${ }^{1}$, have poorer gas exchange status than women with the same BMI 24,25. The abnormally low arterial $\mathrm{PO}_{2}$ and high alveolar-arterial $\mathrm{O}_{2}$ difference values at rest have been mainly attributed to ventilation-perfusion imbalance due to compression of the lung parenchyma by extra-pulmonary adipose tissue ${ }^{30,31}$.

The compelling evidence of lung volume reduction, mainly located in the lower parts of the lung with collapse of the underlying parenchyma provoke atelectasis with absence of alveolar gas, was based on two important studies. Holley et al. ${ }^{32}$ were the first to report regional distributions of ventilation-perfusion relationships using a radioactive xenon technique in severe obese subjects (BMI, $39 \pm$ [SD] $4 \mathrm{~kg} / \mathrm{m}^{2}$ ) when upright. In this study, the distribution of perfusion was predominantly diverted to the lower lung zones, but in half of the subjects, with a lower ERV (ERV < $0.4 \mathrm{~L} ; 21 \%$ predicted), distribution of ventilation was reversed, being the upper lung regions relatively better ventilated than the lower ones, while the dependent zones were under-ventilated inducing the development of airway collapse and atelectasis. Similarly, two years later, Barrera et al. ${ }^{33}$ reported in severe obese subjects the presence of shunt using the mixed venous admixture ratio measurement, suggesting that arterial hypoxaemia was related to over-perfusion of under-ventilated areas and/or to perfusion of completely non-ventilated areas (i.e. intrapulmonary shunt). Moreover, due to the increased presence of airway closure in dependent lung regions, obesity further reduces FRC ${ }^{20,34}$. Airway closure is a physiological phenomenon that occurs during expiration, with or without re-opening of airways during the succeeding inspiration ${ }^{35}$. During ambient air tidal breathing, it is more likely that airways will close in older normal weight subjects (65-70 years) when upright ${ }^{36,37}$. Moreover, the reduction of FRC promotes airway closure in dependent lung regions and this reduction is more marked in Trendelenburg and headdown positions, in which there is a cranial displacement of the diaphragm. Farebrother et $a .^{23}$ observed, in a small subset of 8 severe obese individuals (4 men; BMI, $42 \mathrm{~kg} / \mathrm{m}^{2}$; 7 current smokers), a reduction in ERV below closing volume and a positive relationship between ERV and arterial $\mathrm{PO}_{2}$ (Table 1). Likewise, they demonstrated a close correlation between arterial $\mathrm{PO}_{2}$ and the extent of airway closure within the range of tidal breathing, as a mechanism of basal lung hypoventilation, already previously acknowledged by Holley et al. ${ }^{32}$.

More recently, the pulmonary and non-pulmonary factors of gas exchange were comprehensively investigated using the inert gas technique $^{38}$. This approach, considered to be one of the most robust tools for the assessment of 


\section{Pleural effusion}
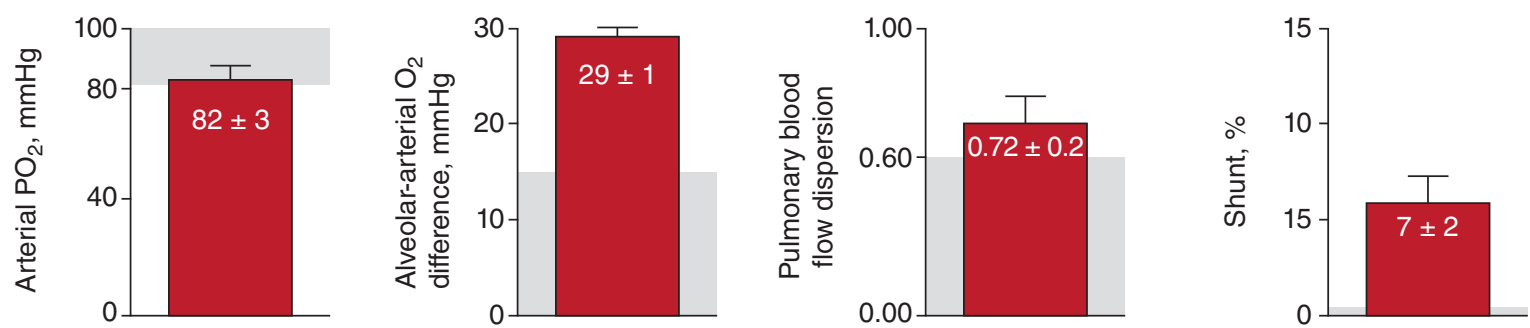

Severe obesity
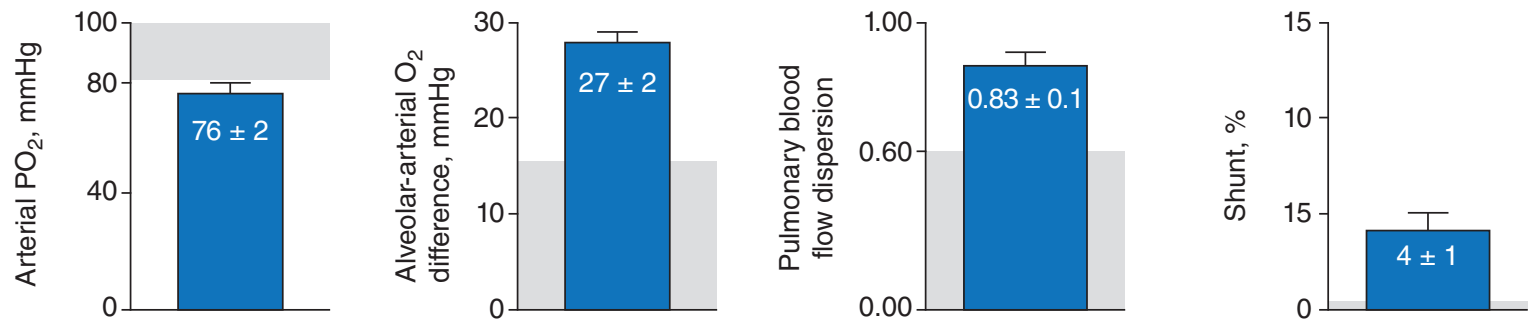

Figure 1. Principal pulmonary gas exchange indices from two studies in patients with pleural effusion (red bars) ${ }^{39}$ and in obese subjects (blue bars ${ }^{30}$. In pleural effusion, although arterial $\mathrm{PO}_{2}$ was within normal limits, alveolar-arterial $\mathrm{O}_{2}$ difference was slightly increased and ventilation-perfusion distributions were broadened, as reflected by an increased blood flow distribution, along with mild intrapulmonary shunt. Note the similarities in all indices between the two clinical conditions, suggesting a similar mechanism, i.e. compression of the lung parenchyma by massive pleural fluid or extra-pulmonary massive adipose tissue. Arterial $\mathrm{PO}_{2}$ and alveolar-arterial $\mathrm{O}_{2}$ difference values are expressed in $\mathrm{mmHg}$, dispersion of pulmonary blood flow is dimensionless, and intrapulmonary shunt in percentage of cardiac output. Shaded areas represent normal limits for each variable (shunt value is almost negligible $[<1 \%$ of cardiac output]).

pulmonary gas exchange, facilitated the thorough unravelling of all pulmonary gas exchange determinants in non-smoking morbidly obese women, with or without moderate-to-severe sleep apnoea, most likely to be extended to males. It was observed that despite a minor reduction of lung volumes, these individuals had pulmonary gas exchange abnormalities characterized by widened alveolar-arterial $\mathrm{O}_{2}$ difference $(27 \pm 2 \mathrm{mmHg})$ and mild arterial hypoxaemia $(76 \pm 2 \mathrm{mmHg}$ ), due to mild-to-moderate increased intrapulmonary shunt (i.e. non-ventilated alveolar units) associated with increased dispersion of pulmonary blood flow and of alveolar ventilation distributions ${ }^{30}$; by contrast, diffusion limitation to oxygen was completely absent. It is of note that the non-pulmonary determinants of pulmonary gas exchange, namely cardiac output, overall ventilation and oxygen consumption, were within normal limits $^{30,31}$. It is also of interest to draw the attention to the finding that, overall, the presence of gas exchange disturbances in the morbidly obese was almost identical to that shown in patients with extensive pleural effusion (liquid volume range, $0.5-1.0 \mathrm{~L}$ ) that mechanically compresses the underlying lung parenchyma. Figure 1 illustrates for comparison the 
pulmonary gas exchange indices of patients with pleural effusion, showing values quite close to those of obese individuals. Although mean arterial $\mathrm{PO}_{2}$ was within normal limits in the latter patients, alveolar-arterial $\mathrm{O}_{2}$ difference was abnormally increased due to an increased dispersion of pulmonary blood flow distribution (which reflects areas with low ventilation-perfusion ratios), with mild increased intrapulmonary shunt ${ }^{39}$. The contention was that pleural effusion induces regions with low ventilation-perfusion ratios mostly related to the degree of lung collapse caused by the accumulation of fluid in the pleural cavity. Accordingly, we may extrapolate the latter contention to the status of obesity-induced gas exchange disturbances. These findings therefore suggest that the very abundant abdominal adipose tissue that characterizes very severe obesity may result in an excessive and unopposed intra-abdominal pressure that mechanically compresses the lower regions of the lungs and provokes areas of low ventilation-perfusion ratios with a mild amount of intrapulmonary shunt. Although the latter conclusion can be compelling, this should not be viewed as prove of this similarity being real as it is based on indirect comparison of data from two different studies 18 years apart.

\section{CHRONIC SYSTEMIC INFLAMMATION AND PERIVASCULAR ADIPOSE TISSUE}

It is well established that obesity is a state of low-grade chronic systemic inflammation ${ }^{40-43}$. In the 1990s, the classical view of adipose tissue as an inert reservoir of energy storage was abandoned because it was demonstrated that: (1) there was a clear link between inflammation, obesity and insulin resistance ${ }^{40-44}$; and, (2) adipose tissue was able to produce adipo-cytokines (adipocyte-derived hormones structurally similar to cytokines), such as leptin and adiponectin. Along these lines, it is of interest to highlight that Arismendi et al. ${ }^{41}$ were able to provide an integrated network analysis of the interplay among the different serum inflammatory markers to characterize the features of inflammome as a network layout of the inflammatory pattern in the morbidly severe obese (Fig. 2). Moreover, it has been suggested that the changes seen in adipose tissue in obesity are likely to have detrimental effects on vasoactive properties of perivascular adipose tissue $^{45}$. Thus, the aberrant secretion of vasoactive molecules from adipose tissues is described as a key link between obesity and endothelial dysfunction, which is characterized by impaired vasodilatation and augmented vasoconstriction ${ }^{43}$. It has been demonstrated that in healthy individuals perivascular adipose tissue has anti-contractile effects ${ }^{45}$ because adipocytes release adiponectin, which maintains endothelial nitrous oxide (NO) production, hence reducing vascular tone in human subcutaneous small arteries. In severe obesity, however, the anti-contractile capacity of perivascular adipose tissue is lost, because individual adipocyte size is greater and, consequently, there is local tissue hypoxia and inflammation. This milieu provides the stimulus for adipocyte and macrophage release of inflammatory cytokines. Both hypoxia and inflammation are known to reduce adiponectin production from adipocytes, so it was demonstrated that these stimuli inhibit the vasorelaxant properties of perivascular adipose tissue through increased oxidative stress. It is important to note 


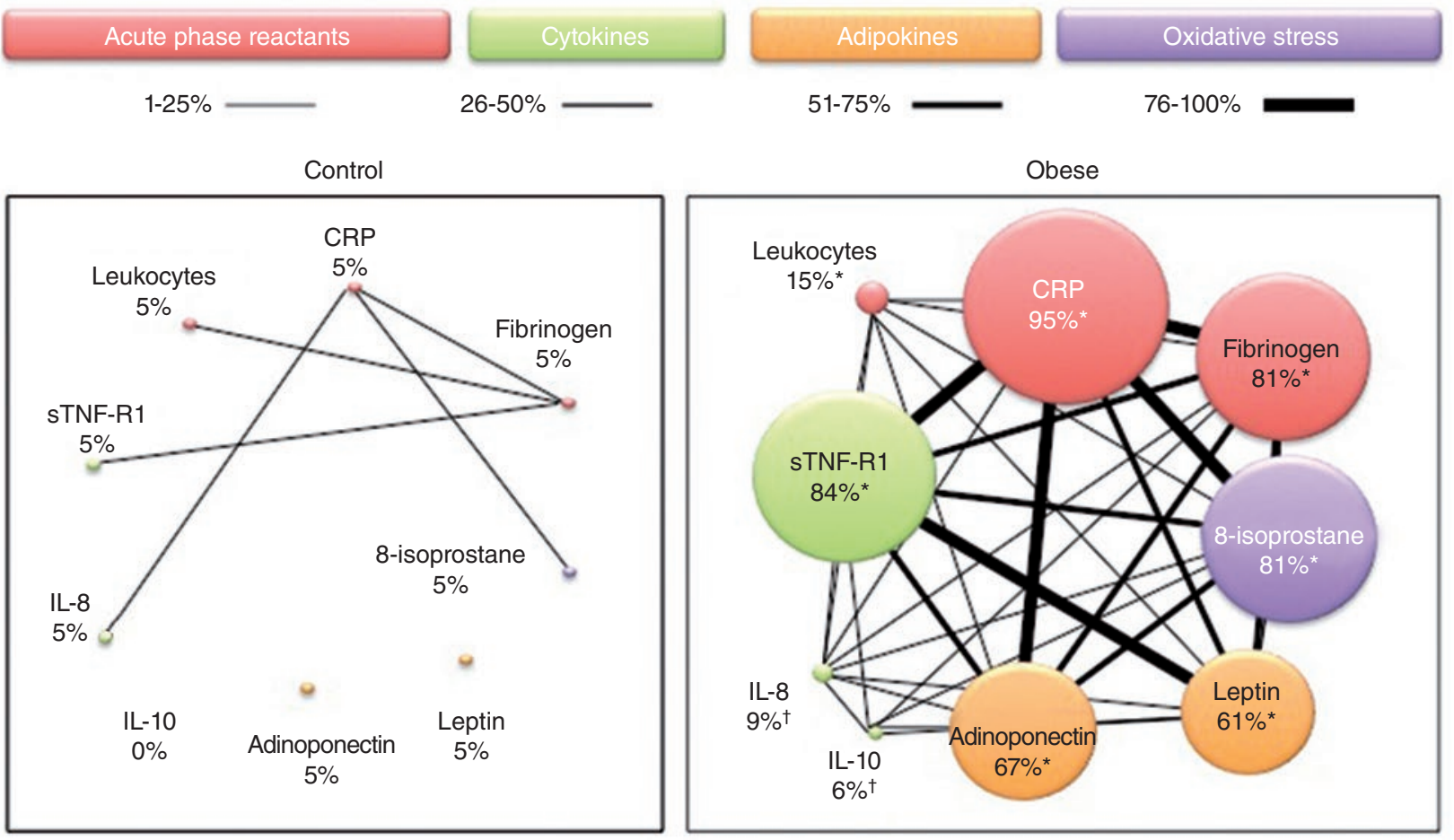

FiguRE 2. Systemic inflammome characterized as a network analysis of the inflammatory pattern in healthy (left) participants and in obese candidates to bariatric surgery (right). Each node represents one inflammatory marker and each colour indicates the type of inflammatory marker considered (acute phase reactants, cytokines, adipokines or oxidative stress). The node diameter is proportional to the prevalence of abnormal values (i.e. 95th or 5th of controls) of that particular biomarker in the population under consideration (control or obese individuals) and the thickness of the edges linking pairs of nodes is proportional to the prevalence of co-occurrence of abnormal biomarkers of that particular pair of nodes. As expected, compared to control, obese individuals exhibited significantly higher mean concentrations of most serum inflammatory biomarkers except for adiponectin, which was lower (adapted with permission from Arismendi $E$ et al. ${ }^{41}$ ).

CRP: C-reactive protein; IL: interleukin; sTNF-R1: soluble tumour necrosis factor-receptor 1.

that the increased serum biomarkers usually observed in morbidly obese individuals are not related to the indices of pulmonary gas exchange disturbances ${ }^{30}$.

\section{OXYGEN-INDUCED PULMONARY GAS EXCHANGE ABNORMALITIES}

In severe obese subjects 100\% oxygen breathing induces a two-fold increase in intrapulmonary shunt without changes in the dispersion of the pulmonary blood flow distribution ${ }^{30}$. However, the bigger the intrapulmonary shunt induced by oxygen breathing, the greater the fall in the dispersion of pulmonary blood flow, a significant association that indicates an abnormal redistribution of pulmonary blood flow (Fig. 3A), with associated systemic haemodynamic changes (increases in the systemic vascular resistance and arterial pressure due to a reduced cardiac output following a decrease in oxygen consumption). Most importantly, the oxygen-induced increment of intrapulmonary 
A

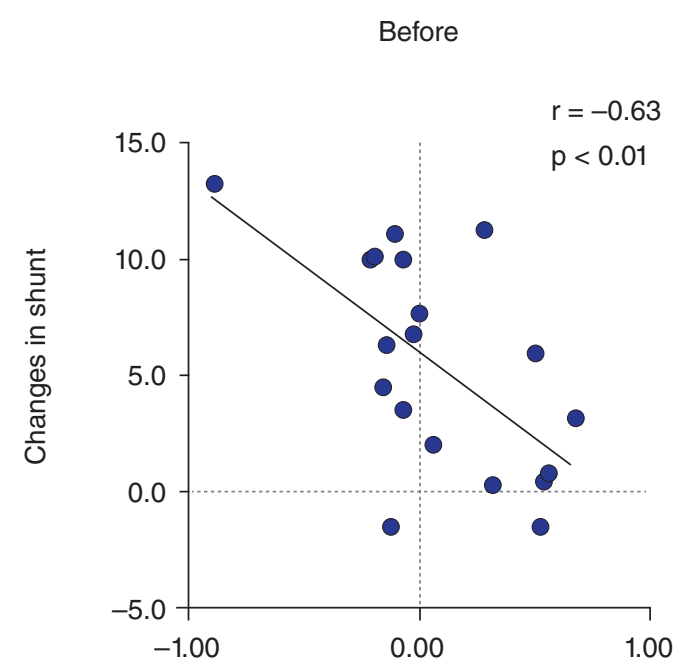

B

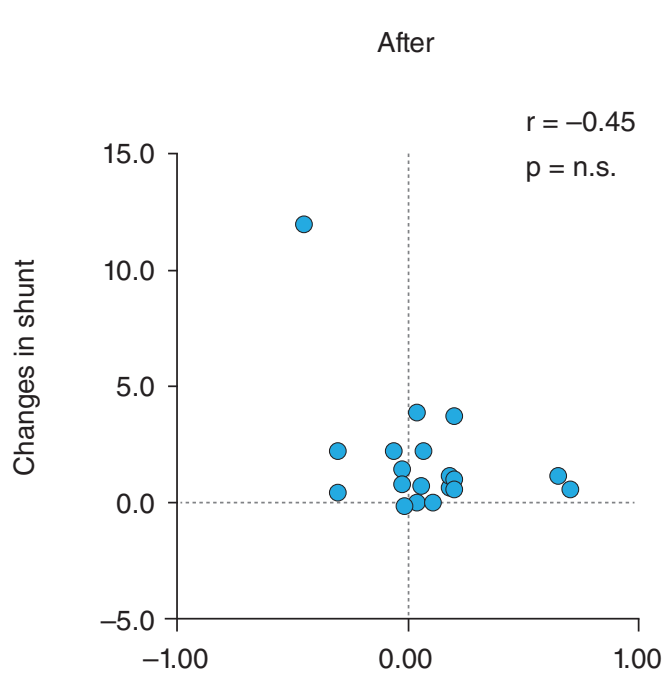

Changes in pulmonary blood flow dispersion

Figure 3. (A) Pre- and (B) post-bariatric surgery plots of the changes between ambient air and 100\% oxygen breathing in intrapulmonary shunt (Y-axis), expressed as a percentage of cardiac output, and in the dispersion of pulmonary blood flow (X-axis) dimensionless, before (dark blue) and after bariatric surgery (light blue). Before surgery, oxygen-induced increases in intrapulmonary shunt were inversely associated with reductions in the dispersion of pulmonary blood flow $(r=-0.63)$, a correlation that remained significant after exclusion of two outlier subject $(r=-0.49 ; p<0.04)$. This correlation was lost after bariatric surgery. Each dot represents an individual participant (reproduced with permission from Rivas $E$ et $a^{30}{ }^{30}$.

shunt observed, likely related to the development of lung areas with reabsorption atelectasis resulting from alveolar denitrogenation $^{46,47}$, was not associated with reversion of hypoxic pulmonary vasoconstriction (as reflected by a lack of change in the dispersion of pulmonary blood flow distribution). Under conditions of hyperoxia, it has been consistently shown that low inspired ventilation-perfusion ratios, named "critical", become unstable and may ultimately collapse, thereby resulting in the development of reabsorption atelectasis ${ }^{48}$. Similarly, the simultaneous increases in mixed venous $\mathrm{PO}_{2}$ also observed in morbid obese individuals during oxygen breathing facilitate the reduction of the pulmonary vascular tone ${ }^{49}$. Overall these findings may well reflect the presence of more rigid and fixed pulmonary vessels due to increased systemic (and perhaps pulmonary) inflammation in the context of an altered perivascular adipose tissue-induced endothelial dysfunction, already demonstrated in the cutaneous circulation ${ }^{50}$. This gas exchange pattern replicates what is usually observed in acute lung injury and acute respiratory distress syndrome (ARDS). Santos et al. ${ }^{47}$ already demonstrated the effects of $100 \%$ oxygen breathing on pulmonary gas exchange indices in two subsets of patients, those with 
acute lung conditions and those with chronic obstructive airway diseases. Like in individuals with extreme obesity, patients with acute respiratory state diseases always significantly increase intrapulmonary shunt during hyperoxic conditions, while the redistribution of pulmonary blood flow remains unaltered; by contrast, those affected by chronic obstructive airway disease (i.e., COPD) always increase the blood flow dispersion distribution, without accompanying changes in the intrapulmonary shunt component, usually discrete under basal conditions, as shown in numerous gas exchange studies ${ }^{49}$. In obese subjects there is an accumulation of adipose tissue in the vascular walls of the systemic circulation, and even perhaps in the pulmonary vascular bed. All in all, these findings point to an abnormal pulmonary vascular likelihood in morbidly obese subjects underlying the abnormal gas exchange pattern of hyperoxic response ${ }^{50}$.

A model including the lungs, bone marrow, and adipose tissue as major components of a vascular interconnected network, that channels biological signals and facilitates their interaction, has been postulated for COPD ${ }^{51}$. Consequently, it has been suggested that the lung parenchyma and the systemic endothelium could act as the main external and internal sensors of the system, respectively, whereas the bone marrow and the adipose tissue are two important responding elements. According to this hypothesis, the development of COPD and associated multi-morbidities including obesity, may depend on the manner in which the interacting network responds, adapts, or fails to adapt (as modulated by the genetic and epigenetic background of the individual) to the initial pulmonary injury originally induced by inhaling those toxic gases and particles. This hypothetical model might well represent, at least in part, a complementary biologic mechanism to explain the altered perivascular adipose tissue shown in severe obesity.

\section{POSTURAL-INDUCED GAS EXCHANGE ABNORMALITIES (ORTHODEOXIA]}

Most tellingly, orthodeoxia (upright-induced arterial deoxygenation from recumbency) can be present in morbid obese individuals with arterial hypoxaemia at rest ${ }^{31}$, just as shown in other well-known conditions, such as opening of foramen ovale 52 and hepatopulmonary syndrome $^{53}$. In the latter condition, the basic mechanism is due to further ventilation-perfusion worsening that reflects the development of more areas with low ventilation-perfusion ratios combined with some degree of increased intrapulmonary shunt. Presumably, this hepatic pattern of orthodeoxia reflects a more altered pulmonary vascular tone, more rigid and fixed, heterogeneously distributed so less liable to proportionately accommodate gravitational pulmonary blood flow changes to alveolar ventilation in dependent alveolar units. By contrast, in hypoxaemic morbidly obese subjects, oxygenation worsens when upright, as discretely as in liver diseases, because cardiac output decreases due to a simultaneous reduced venous return, without further ventilation-perfusion worsening ${ }^{31}$. Importantly, the critical difference in the obese pulmonary vasculature response is plausibly related to the distinct effects of $100 \%$ oxygen breathing. In severe obesity, hypoxic pulmonary vasoconstriction is not reversed during 
hyperoxic breathing, at variance with the usual release of hypoxic pulmonary vasoconstriction observed in chronic respiratory or liver disease states ${ }^{49,54}$. As alluded to above, this is likely due to the presence of increased perivascular adipose tissue, with changes in extra-vascular lung water (see below), related to the underlying low-grade chronic systemic and lung inflammation ${ }^{41,55}$. Should increases in cardiac output in the morbidly obese individuals be accompanied by higher increases in intrapulmonary shunt when supine, the net effect would have ultimately offset the observed improvement in arterial oxygenation.

\section{LUNG IMAGING FINDINGS}

High resolution thoracic computerized tomography (CT) scanning is currently considered one of the highest gold standards for evaluation of pulmonary structure and lung volumes $^{56}$. In 1995, the definition of atelectasis as non-aerated lung volume (NALV) with a threshold density in CT scan between -100 to +100 Hounsfield units (HU) was established. This density analysis allows the quantification of atelectasis in relation to the total lung area. Using this density analysis, several studies have shown that impaired gas exchange in morbidly obese individuals during general anaesthesia is related to a higher development of atelectasis than in lean subjects ${ }^{57-60}$. More recently, a new approach of non-contrast thoracic CT imaging to quantify changes in pulmonary vascular volume has been reported together with $\mathrm{CT}$ assessment of total lung tissue volume (Vtiss) defined as the volume of the lung not occupied by air. If large airways and vessels are excluded from the overall measurement as part of its definition, Vtiss therefore represents the volume occupied by parenchymal tissue and by pulmonary small vessels and capillaries $^{61,62}$. Thus, changes in Vtiss reflect all fluid changes within the lung including blood and interstitial fluids. Accordingly, an increase in Vtiss could also be caused by increases in pulmonary capillary blood volume and in the segmented vascular volume and/or by an increase of fluid in the parenchyma interstitial space. Using non-contrast $\mathrm{CT}^{63}$, it was possible to demonstrate an association between the cross-sectional area of pulmonary vessels with lung function ${ }^{64}$ or pulmonary haemodynamics in selected cohorts of patients ${ }^{65}$.

Santos et al. ${ }^{55}$ used this imaging approach to assess lung volumes in morbidly obese subjects and found that the densitometry analysis showed that hypo-aerated lung volume $(-500$ to $-100 \mathrm{HU})$ was higher in obese individuals before bariatric surgery compared to normal-weighted subjects without differences at the end-expiratory lung volume and non-aerated lung volume $(-100$ to $+100 \mathrm{HU})$ (Fig. 4). Importantly, it was observed that Vtiss in obese participants ${ }^{55}$, whether or not standardized by body height, was higher than in control subjects, although within the normal limits (Fig. 5) ${ }^{58,63}$. Taken as a whole, this very novel difference was not associated with changes in the total area of CT visible vessels, neither with changes in systemic and pulmonary haemodynamics or small vessel areas $\left(3 \mathrm{~mm}^{2}<\right.$ area $\left.<5 \mathrm{~mm}^{2}\right)$. Given that the pulmonary vascular blood volume remained equal, differences in Vtiss should track the changes in volume of the lung parenchymal tissue or interstitial fluid. 

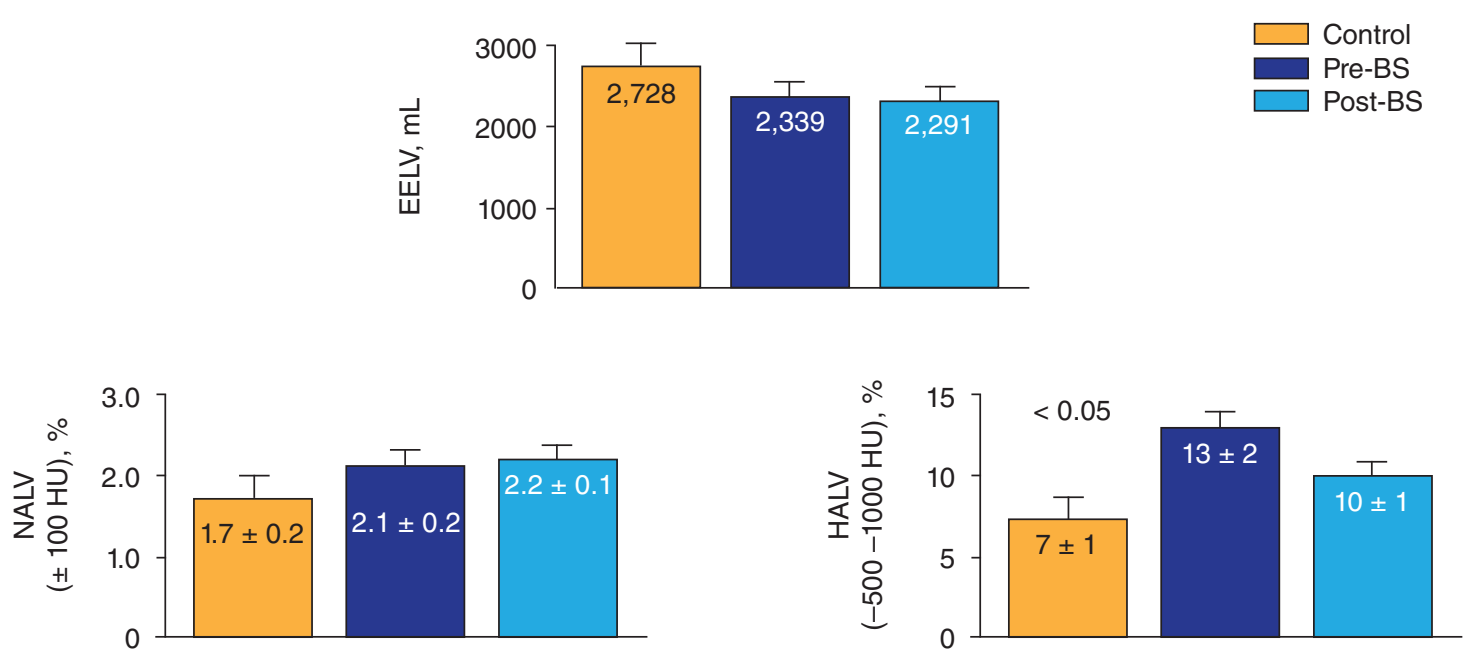

Figure 4. Thoracic computerized tomography (CT) density analysis of lung volumes measured in control (golden bars) individuals while compared to obese subjects, before (dark blue bars) and after (light blue bars) bariatric surgery (BS). Compared to normal weighted, obese individuals showed a higher hypo-aerated lung volume (HALV; -500 to -100 Hounsfield units [HU]), without differences in end-expiratory volume (EELV) and non-aerated lung volume (NALV; -100 to $+100 \mathrm{HU})$. After bariatric surgery, no significant changes were observed.

\section{THE EFFECTS OF BARIATRIC SURGERY}

Bariatric surgery is well tolerated, has a profound weight-reduction effect ${ }^{14,15}$ and reverses the obesity-induced low-grade inflammation ${ }^{41,66}$ while restoring the function of perivascular adipose tissue by reducing adipose inflammation and increasing local adiponectin and $\mathrm{NO}$ bioavailability $^{50}$. Along with significant weight loss and reduction of systemic inflammation after bariatric surgery, all pulmonary gas exchange disturbances, including postural-induced derangements, were also considerably improved but not completely abolished, akin to the usual bariatric surgery remnants of mild obesity and systemic inflammation, since all serum inflammatory biomarkers decreased but remained still somehow abnormal. Although mechanical factors

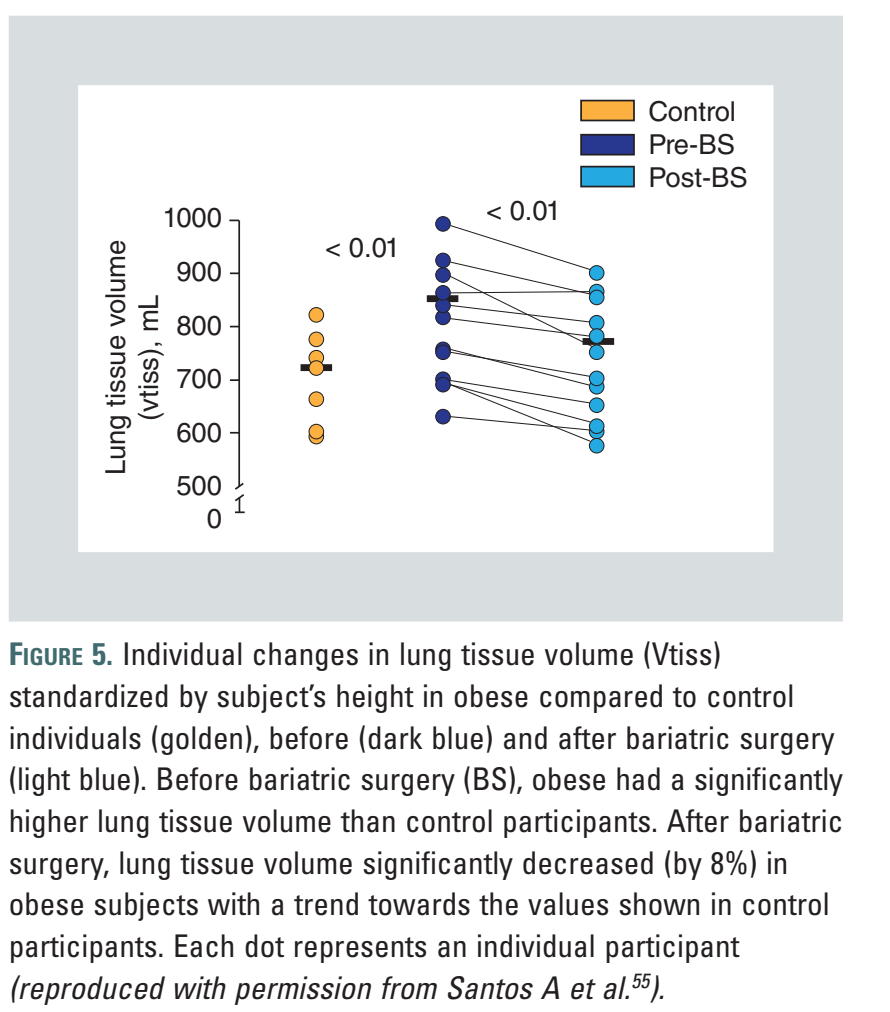


can undoubtedly play a role, the finding that the correlation between oxygen-induced changes in intrapulmonary shunt and in the dispersion of pulmonary blood flow post-bariatric surgery was lost (Fig. 3B), points to a substantial improvement in pulmonary blood flow redistribution ${ }^{30}$. Hence, these findings could support a causal role of obesity on gas exchange and vascular tone abnormalities in the lungs. Moreover, there is a significant improvement of arterial $\mathrm{PO}_{2}$ while breathing $100 \%$ oxygen after bariatric surgery that can be explained by the reduction of intrapulmonary shunt observed after surgery ${ }^{30,31}$.

Despite this marked reduction in intrapulmonary shunt after bariatric surgery, CT densitometry data did not show any change at the CT-lung volumes, namely end-expiratory volume, non-aerated lung volume, hypo-aerated lung volume (Fig. 4). Most likely, this can be also explained by the higher variability along with a slightly lower resolution of CT lung imaging, a topographical approach, compared to the power of the state-of-the art inert gases approach. Accordingly, if we consider, first, that the latter finding fails to include the pulmonary blood flow within the non-ventilated areas and, second, that it can be a more sensitive and less variable tool than lung imaging to detect the amounts of intrapulmonary shunt, it should be expected to observe more noticeable changes on inert gas shunt and less on imaging hypo-aerated and non-aerated lung areas. By contrast, there was a significant reduction of Vtiss in the obese participants (Fig. 5) without associated reductions in the post-operative vascular area (i.e. pulmonary vessels $<5 \mathrm{~mm}^{2}$ ) after bariatric surgery ${ }^{55}$. Neither were correlations between changes in Vtiss and any pulmonary haemodynamic changes. Given that the pulmonary vascular blood volume remained unchanged, Vtiss variations should track the changes in volume of the lung parenchymal tissue. It is therefore conceivable that before bariatric surgery systemic (and pulmonary as well) inflammation could have increased extra-vascular lung water, thereby being in part responsible for the elevated pre-bariatric surgery Vtiss in obese subjects compared with controls and for its subsequent reduction after bariatric surgery. Accordingly, these findings are consistent with the presence of increased serum inflammatory biomarkers before bariatric surgery and their post-operative reduction. In addition, changes in Vtiss could have also been related to a potential reduction in systemic (and perhaps pulmonary) inflammation after bariatric surgery ${ }^{41,66}$ which would be consistent with the improvement in all pre-bariatric surgery pulmonary gas exchange disturbanc$\mathrm{es}^{30,31}$. However, at present it is not possible to unravel which of these mechanisms was more influential.

\section{CONCLUSIONS}

Obesity-induced pulmonary gas exchange abnormalities (increased alveolar-arterial $\mathrm{O}_{2}$ difference with or without mild hypoxaemia) in non-smoking morbidly obese candidates to bariatric surgery are linked to ventilation-perfusion imbalance, namely mild-to-moderate intrapulmonary shunt and increased dispersions of pulmonary blood flow and ventilation distributions. These abnormalities can be secondary to thoracic and abdominal compression by extra-pulmonary adipose tissue that reduces chest volume; most tellingly, during hyperoxic conditions, intrapulmonary shunt increases 
without reversion of hypoxic pulmonary vasoconstriction. This may well reflect a less responsive pulmonary vasculature in the context of low-grade chronic systemic inflammation. Altogether these findings are consistent with an increased Vtiss in the morbidly obese compared to lean individuals and may be related to elevated extra-vascular lung water (due to low-grade systemic inflammation). Bariatric surgery induces weight loss, reduces systemic inflammation and likely pulmonary perivascular adipose tissue, thus considerably improving lung volumes and pulmonary gas exchange defects, with Vtiss reduction. In sum, bariatric surgery is associated with an effective reversion of the obese-induced lung function and imaging disturbances in addition to reducing fat tissue in morbidly obese individuals.

\section{CONFLICT OF INTEREST}

Dr. Eva Rivas, Dr. José G Venegas and Dr. Robert Rodriguez-Roisin have nothing to disclose.

Supported by: Fondo de Investigación Sanitaria (FIS) PI 080311, CIBERES, and the Generalitat de Catalunya (2014SGR661). Consejería de Educación, Juventud y Deporte of the Comunidad de Madrid and the People Programme (Marie Curie Actions) of the European Union's Seventh Framework Programme (FP7/20072013) under REA grant agreement $n^{\circ} 291820$ Grant from Almirall.

\section{REFERENCES}

1. Vague J. Sexual differentiation. A determinant factor of the forms of obesity. 1947. Obes Res. 1996;4:201-3.

2. Eckel RH, Grundy SM, Zimmet PZ, Alberti KGMM. The metabolic syndrome. Lancet. 2010;375:181-3.
3. Alberti KGMM, Eckel RH, Grundy SM et al. Harmonizing the metabolic syndrome: a joint interim statement of the International Diabetes Federation Task Force on Epidemiology and Prevention; National Heart, Lung, and Blood Institute; American Heart Association; World Heart Federation; International Circulation. 2009;120:1640-5.

4. World Health Organization Global Health Observatory. Obesity: Situation and trends. www.who.int/gho/ncd/risk_factors/obesity_text/en/. Date last accessed September 15, 2017.

5. World Health Organization. Obesity: preventing and managing the global epidemic. 2000.

6. World Health Organization. Global status report on noncommunicable diseases 2014. World Health 2014

7. $\mathrm{Ng} \mathrm{M}$, Fleming $\mathrm{T}$, Robinson $\mathrm{M}$ et al. Global , regional , and national prev alence of overweight and obesity in children and adults during 1980 2013 : a systematic analysis for the Global Burden of Disease Study 2013 Lancet. 2014;9945:766-81

8. Whitlock G, Lewington S, Sherliker P et al. Body-mass index and cause-specific mortality in 900000 adults: collaborative analyses of 57 prospective studies. Lancet. 2009;373:1083-96.

9. Marz M, Haluzik M, Mraz M, Haluzik M. The role of adipose tissue immune cells in obesity and low-grade inflammation. J Endocrinol. 2014;1-35.

10. Poirier P, Giles TD, Bray G a et al. Obesity and cardiovascular disease: pathophysiology, evaluation, and effect of weight loss: an update of the 1997 American Heart Association Scientific Statement on Obesity and Heart Disease from the Obesity Committee of the Council on Nutrition, Physical. Circulation. 2006;113:898-918.

11. Colquitt JL, Pickett K, Loveman E, Frampton GK. Surgery for weight loss in adults. Cochrane database Syst Rev. 2014;8:CD003641.

12. Ortega E, Morinigo R, Flores L et al. Predictive factors of excess body weight loss 1 year after laparoscopic bariatric surgery. Surg Endosc. 2012;26: 1744-50.

13. Vidal J, Ibarzabal A, Nicolau J et al. Short-term effects of sleeve gastrectomy on type 2 diabetes mellitus in severely obese subjects. Obes Surg. 2007;17:1069-74.

14. Jiménez A, Casamitjana R, Flores L et al. Long-Term Effects of Sleeve Gastrectomy and Roux-en-Y Gastric Bypass Surgery on Type 2 Diabetes Mellitus in Morbidly Obese Subjects. Ann Surg. 2012;256:1023-9.

15. Schauer PR, Kashyap SR, Wolski K et al. Bariatric surgery versus intensive medical therapy in obese patients with diabetes. N Engl J Med. 2012;366: 1567-76.

16. Flum DR, Salem L, Elrod JAB, Dellinger EP, Cheadle A, Chan L. Early mortality among Medicare beneficiaries undergoing bariatric surgical procedures. JAMA. 2005;294:1903-8.

17. Birkmeyer JD, Finks JF, O'Reilly A et al. Surgical skill and complication rates after bariatric surgery. N Engl J Med. 2013;369:1434-42.

18. Jones RL, Nzekwu MM. The effects of body mass index on lung volumes. Chest. 2006;130:827-33.

19. Pelosi $\mathrm{P}$, Croci M, Ravagnan I et al. Respiratory system mechanics in sedated, paralyzed, morbidly obese patients. J Appl Physiol. 1997;82:811-8.

20. Salome CM, King GG, Berend N. Physiology of obesity and effects on lung function. J Appl Physiol. 2010;108:206-11.

21. Beuther DA, Weiss ST, Sutherland ER. Obesity and asthma. Am J Respir Crit Care Med. 2006;174:112-9.

22. Gabrielsen A-M, Lund MB, Kongerud J, Viken KE, Røislien J, Hjelmesæth J. The relationship between anthropometric measures, blood gases, and lung function in morbidly obese white subjects. Obes Surg. 2011;21:485-91.

23. Farebrother MJ, McHardy GJ, Munro JF. Relation between pulmonary gas exchange and closing volume before and after substantial weight loss in obese subjects. Br Med J. 1974;3:391-3.

24. Zavorsky GS, Christou N V, Kim do J, Carli F, Mayo NE. Preoperative gender differences in pulmonary gas exchange in morbidly obese subjects. Obes Surg. 2008;18:1587-98.

25. Zavorsky GS, Murias JM, Kim DJ, Gow J, Sylvestre J-L, Christou N V. Waist-to-hip ratio is associated with pulmonary gas exchange in the morbidly obese. Chest. 2007;131:362-7. 
26. Zavorsky GS, Hoffman SL. Pulmonary gas exchange in the morbidly obese. Obes Rev. 2008;9:326-39.

27. Vaughan RW, Cork RC, Hollander D. The effect of massive weight loss on arterial oxygenation and pulmonary function tests. Anesthesiology. 1981;54: 325-8.

28. Vaughan RW, Wise L. Postoperative arterial blood gas measurement in obese patients: effect of position on gas exchange. Ann Surg. 1975;182:705-9.

29. Thomas PS, Cowen ER, Hulands G, Milledge JS. Respiratory function in the morbidly obese before and after weight loss. Thorax. 1989;44:382-6.

30. Rivas E, Arismendi E, Agustí A et al. Ventilation/Perfusion Distribution Abnormalities In Morbidly Obese Subjects Before and After Bariatric Surgery. Chest. 2015;147:1127-34.

31. Rivas E, Arismendi E, Agusti A, Gistau C, Wagner PD, Rodriguez-Roisin R. Postural effects on pulmonary gas exchange abnormalities in severe obesity before and after bariatric surgery. Minerva Anestesiol. 2016;82: 403-10.

32. Holley HS, Milic-Emili J, Becklake MR, Bates D V. Regional distribution of pulmonary ventilation and perfusion in obesity. J Clin Invest. 1967;46: 475-81.

33. Barrera F, Reidenberg MM, Winters WL, Hungspreugs S. Ventilation-perfusion relationships in the obese patient. J Appl Physiol. 1969;26:420-6.

34. Mahadev S, Salome CM, Berend N, King GG. The effect of low lung volume on airway function in obesity. Respir Physiol Neurobiol. 2013;188:192-9.

35. Milic-Emili J, Torchio R, D’Angelo E. Closing volume: a reappraisal (19672007). Eur J Appl Physiol. 2007;99:567-83.

36. Rusca M, Proietti S, Schnyder P et al. Prevention of Atelectasis Formation During Induction of General Anesthesia. Anesth Analg. 2003;97:1835-9.

37. Rothen HU, Sporre B, Engberg G, Wegenius G, Hedenstierna G. Airway closure, atelectasis and gas exchange during general anaesthesia. Br J Anaesth. 1998;81:681-6.

38. Wagner PD, Saltzman HA, West JB. Measurement of continuous distributions of ventilation-perfusion ratios: theory. J Appl Physiol. 1974;36:588-99.

39. Agusti AG, Cardus J, Roca J, Grau JM, Xaubet A, Rodriguez-Roisin R. Ventilation-perfusion mismatch in patients with pleural effusion: effects of thoracentesis. Am J Respir Crit Care Med. 1997;156:1205-9.

40. Hotamisligil GS. Inflammation and metabolic disorders 1. Nature. 2006;444: 860-7.

41. Arismendi E, Rivas E, Agustí A et al. The systemic inflammome of severe obesity before and after bariatric surgery. PLoS One. 2014;9:e107859.

42. Mancuso P. Obesity and lung inflammation. J Appl Physiol. 2010;108:722-8.

43. Gu P, Xu A. Interplay between adipose tissue and blood vessels in obesity and vascular dysfunction. Rev Endocr Metab Disord. 2013;14:49-58.

44. Feingold KR, Soued M, Staprans I et al. Effect of tumor necrosis factor (TNF) on lipid metabolism in the diabetic rat. Evidence that inhibition of adipose tissue lipoprotein lipase activity is not required for TNF-induced hyperlipidemia. J Clin Invest. 1989;83:1116-21.

45. Greenstein AS, Khavandi K, Withers SB et al. Local inflammation and hypoxia abolish the protective anticontractile properties of perivascular fat in obese patients. Circulation. 2009;119:1661-70.

46. Dantzker DR, Wagner PD, West JB. Instability of lung units with low Va/Q ratios during O2 breathing. J Appl Physiol. 1975;38:886-95.

47. Santos C, Ferrer M, Roca J et al. Pulmonary gas exchange response to oxygen breathing in acute lung injury. Am J Respir Crit Care Med. 2000;161:26-31.

48. Dantzker DR, Brook CJ, Dehart P, Lynch JP, Weg JG. Ventilation-perfusion distributions in the adult respiratory distress syndrome. Am Rev Respir Dis. 1979;120:1039-52.
49. Rodriguez-Roisin R. Nonpulmonary influences on gas exchange. Compr Physiol. 2014;4:1455-94.

50. Aghamohammadzadeh R, Greenstein AS, Yadav R et al. Effects of Bariatric Surgery on Human Small Artery Function Evidence for Reduction in Perivascular Adipocyte Inflammation, and the Restoration of Normal Anticontractile Activity Despite Persistent Obesity. J Am Coll Cardiol. 2013;62: 128-35.

51. Agusti A, Barberà JA, Wouters EFMM, Peinado VI, Jeffery PK, Agustí A. Lungs, bone marrow and adipose tissue: a network apporach to the pathobiology of chronic obstructive pulmonary disease. Am J Respir Crit Care Med. 2013;188:1-46.

52. Knapper JT, Schultz J, Das G, Sperling LS. Cardiac platypnea-orthodeoxia syndrome: An often unrecognized malady. Clin Cardiol.2014;37:645-9.

53. Gómez FP, Martínez-Pallí G, Barberà JA, Roca J, Navasa M, Rodríguez-Roi$\sin$ R. Gas exchange mechanism of orthodeoxia in hepatopulmonary syndrome. Hepatology. 2004;40:660-6.

54. Rodriguez-Roisin R, Roca J, Agusti AG, Mastai R, Wagner PD, Bosch J. Gas exchange and pulmonary vascular reactivity in patients with liver cirrhosis Am Rev Respir Dis. 1987;135:1085-92.

55. Santos A, Rivas E, Rodríguez-Roisin R et al. Lung Tissue Volume is Elevated in Obesity and Reduced by Bariatric Surgery. Obes Surg. 2016;26:2475-82.

56. Rouby J-J, Puybasset L, Nieszkowska A, Lu Q. Acute respiratory distress syndrome: lessons from computed tomography of the whole lung. Crit Care Med. 2003;31:S285-95.

57. Coussa M, Proietti S, Schnyder P et al. Prevention of Atelectasis Formation During the Induction of General Anesthesia in Morbidly Obese Patients. Anesth Analg. 2004;1491-5.

58. Reinius H, Jonsson L, Gustafsson S et al. Prevention of atelectasis in morbidly obese patients during general anesthesia and paralysis: a computer ized tomography study. Anesthesiology. 2009;111:979-87.

59. Talab HF, Zabani IA, Abdelrahman HS et al. Intraoperative ventilatory strategies for prevention of pulmonary atelectasis in obese patients undergoing laparoscopic bariatric surgery. Anesth Analg. 2009;109:1511-6.

60. Eichenberger a-S, Proietti S, Wicky S et al. Morbid obesity and postoperative pulmonary atelectasis: an underestimated problem. Anesth Analg. 2002; 95 1788-92.

61. Ceridon ML, Snyder EM, Strom NA, Tschirren J, Johnson BD. Influence of Rapid Fluid Loading on Airway Structure and Function in Healthy Humans. J Card Fail. 2012;29:997-1003.

62. Cressoni M, Gallazzi E, Chiurazzi C et al. Limits of normality of quantitative thoracic CT analysis. Crit Care. 2013;17:R93.

63. Fuld MK, Halaweish AF, Haynes SE, Divekar AA, Guo J, Hoffman EA Pulmonary perfused blood volume with dual-energy CT as surrogate for pulmonary perfusion assessed with dynamic multidetector CT. Radiology. 2013;267:747-56.

64. Matsuoka S, Washko GR, Dransfield MT et al. Quantitative CT Measurement of Cross-sectional Area of Small Pulmonary Vessel in COPD: Correlations with Emphysema and Airflow Limitation. Acad Radiol. 2010;17:93-9.

65. Matsuoka S, Washko GR, Yamashiro T et al. Pulmonary hypertension and computed tomography measurement of small pulmonary vessels in severe emphysema. Am J Respir Crit Care Med. 2010;181:218-25.

66. Arismendi E, Rivas E, Vidal J et al. Airway Hyperresponsiveness to Mannitol in Obesity Before and After Bariatric Surgery. Obes Surg. 2015;25:1666-71.

67. Hakala K, Mustajoki P, Aittomäki J, Sovijärvi AR. Effect of weight loss and body position on pulmonary function and gas exchange abnormalities in morbid obesity. Int J Obes. Relat. Metab. Disord. 1995;19:343-6. 